Max-Planck-Institut für demografische Forschung

Max Planck Institute for Demographic Research

Konrad-Zuse-Strasse 1 - D-18057 Rostock - GERMANY

Tel +49 (0) 3812081 - 0; Fax +49 (0) 3812081 - 202;

http://www.demogr.mpg.de

MPIDR WORKING PAPER WP 2010-009

FEBRUARY 2010 (REVISED DECEMBER 2010)

\title{
The relative importance of shocks in cohorts' early and later life conditions on age-specific mortality
}

Mikko Myrskylä (myrskyla@demogr.mpg.de)

(C) Copyright is held by the authors.

Working papers of the Max Planck Institute for Demographic Research receive only limited review. Views or opinions expressed in working papers are attributable to the authors and do not necessarily reflect those of the Institute. 
September 10, 2010

\title{
The relative importance of shocks in cohorts' early and later life conditions on age- specific mortality
}

\author{
Mikko Myrskylä ${ }^{1}$
}

\begin{abstract}
The relative importance of cohorts' early life conditions, compared to later period conditions, on adultand old-age mortality is not known. This paper studies how cohort-level mortality depends on shocks in cohorts’ early and later life (period) conditions. I use cohorts' own mortality as a proxy for the early life conditions, and define shocks as deviations from trend. Using historical data for five European countries I find that shocks in early life conditions are only weakly associated with cohorts' later mortality. This may be because individual-level health is robust to early life conditions, or because at the cohort-level scarring, selection and immunity cancel each other. Shocks in period conditions, measured as deviations from trend in period child mortality, are strongly and positively correlated with mortality at all older ages. The results suggest that at the cohort-level changing period conditions drive mortality variation and change.
\end{abstract}

Word count for abstract: 144

Word count for main text: 7,698

1 Research Group: Lifecourse Dynamics and Demographic Change, Max Planck Institute for Demographic Research, Konrad-Zuse-Str. 1, 18057 Rostock, Germany. Email myrskyla@demogr.mpg.de. 


\section{INTRODUCTION}

Understanding the relative importance of early life conditions versus later life period conditions to oldage mortality is crucial for understanding historical mortality decline and for predicting future developments in mortality. For any given period, a cohort's mortality is affected by the period conditions. Research dating back to at least Kermack et al. $(1934,2001)$ as well as more recent studies (Barker 1995; Bengtsson and Lindstrom 2000; Case, Fertig and Paxson 2005; Elo and Preston 1992; Hayward and Gorman 2004; van den Berg, Lindeboom and Portrait 2006) suggest that in addition to period conditions, early life conditions may have an important influence on cohorts' adult- and old-age mortality. It is, however, not known how important early life conditions are when compared to period conditions.

Prior research has demonstrated that cohorts born within a short time interval may experience different mortalities at specific ages or even over their life courses. These cohort differences, which are sometimes interpreted as signifying “cohort effects” on mortality, are well documented (for example, Wilmoth, Vallin and Caselli 1990). The sources of these differences, however, remain uncertain. Early life conditions are one potential source of the differences in cohort mortality. Indeed, it has been shown that early life conditions and adult health and mortality are linked at the individual and cohort-level. However, the evidence regarding the importance of cohort's early life conditions on later life mortality is mixed and debated (Bengtsson and Lindstrom 2000; Finch and Crimmins 2004; Barbi and Vaupel 2005; Catalano and Bruckner 2006; Bengtsson and Brostrom 2009; Bengtsson and Mineau 2009; Gagnon and Mazan 2009; van den Berg, Doblhammer and Christensen 2009). In short, the absolute and relative importance of a cohort's early life experiences for later mortality is uncertain, although it is well recognized that period conditions shape period mortality patterns (see, for example, Oeppen and Vaupel 2002). 
This paper examines the effects of cohort-level early life conditions on later adult- and old-age mortality, and studies how these lagged effects from early to later life compare with the effects of later life period conditions. I use historical time series for five European countries and mortality as a proxy for broad epidemiological and socioeconomic conditions including nutrition and disease load. The results show that shocks that increase cohorts' early life mortality above trend have, on average, only weak lagged effects on adult- and old-age mortality, and especially so when compared to the effects of shocks in period conditions. In addition, the effects of shocks in early life conditions are most pronounced soon after the shock (at ages below 20) and are smaller at old ages. The findings are consistent with the emerging literature suggesting that cohorts’ old-age mortality is not strongly linked to the cohorts' early life mortality (Bruckner and Catalano 2009; van den Berg et al. 2009), and suggest that the majority of variation in adult- and old-age mortality is attributable to changing period rather than changing early life conditions.

\section{BACKGROUND}

It is obvious almost by definition that period conditions at older ages affect old-age mortality. The other side of the coin, the idea that early life conditions could also affect old-age mortality and produce cohort differences, dates back to at least 1934 when Kermack et al. compared age specific mortality rates in England and Wales in 1855-1925 to baseline mortality in 1845. Kermack et al. and found that cohorts seemed to carry with them the same relative mortality throughout life. The conclusion by Kermack et al., that "the health of the man is determined by the physical constitution which the child has built up”, is essentially a life course interpretation of adult health. Preston and van der Walle (1978) used similar methods to analyze urban French mortality in the $19^{\text {th }}$ century and also found a pattern that suggested a cohort decline in adult mortality. In recent decades, interest in the effects of early life conditions on adult health and mortality has been revitalized by Barker and colleagues (Barker 1995; Barker et al. 2002; Eriksson et al. 1999), who stress the importance of nutrition on later life health. 
Few studies have attempted to compare the relative importance of early versus later life period conditions, despite the wide interest in the effects of early life conditions and occasional explicit calls to do so (for example, Catalano and Bruckner 2006, p. 1269: "Further research should, in fact, estimate the relative contribution of cohort and period effects to age-specific mortality”). ${ }^{1}$ The number of studies that take an exclusive cohort perspective and do not compare the effects of early life conditions to period effects is markedly larger. While many of these studies have found links between early life conditions and later life mortality, the overall evidence is mixed. Almond (2006) analyses U.S. data and finds elevated disability rates for those in utero during the 1918 influenza. Mazumber et al. (2009) uses the same 1918 influenza as an exogenous shock and find that those exposed to disease in utero have elevated cardiovascular disease prevalence. Cohen et al. (2010), however, analyze data from 24 countries and find no long-term mortality effects for prenatal or neonatal exposure to the 1918 influenza. The studies by Almond and Mazumber et al. identify the timing of exposure more accurately than Cohen et al., which may explain the difference in results. It is also possible that old-age health but not mortality is sensitive to early life exposure to disease.

Studies on the long-term impact of early life nutritional deprivation have also produced mixed results. Studies on the Finnish famine of 1866-1868 (Kannisto, Christensen and Vaupel 1997) and the Dutch famine of 1944-1945 (Painter et al. 2005) have found no association between nutritional deprivation early in life and later mortality. Van den Berg et al. (2007) analyze the effects of 1846-47 Dutch potato famine and find that men who were exposed to the famine in utero have increased mortality at ages above 50, but find no effects for women. In contrast to these results, Fogel (2004) and Costa and Lahey (2005) attribute much of the decline in old age mortality to improved nutrition.

The most consistent evidence regarding cohort-level links between early life conditions and later life mortality uses the state of the business cycle at birth as a proxy for early life conditions. For example, van den Berg and colleagues $(2006,2008,2009)$, studying $19^{\text {th }}$-early $20^{\text {th }}$ century Danish and Dutch 
cohorts, find that being born in a recession versus boom is associated with increased old-age mortality, especially cardiovascular disease mortality. A study on the 1930s depression in the U.S., however, did not find any long-lasting health effects for those born during the Depression (Cutler, Miller and Norton 2007). This finding could be interpreted so that the boom/bust effect on later life health may have attenuated over time.

Only a few papers have attempted to explicitly compare the effects of early life and later period conditions. In a series of papers, Crimmins and Finch (2004, 2006a, 2006b) regress cohorts’ old-age mortality on early life cohort mortality and period mortality using historical data for several European countries. They find that a cohort's early life conditions, proxied by early life mortality, explain almost all (87-96 \%) of mortality variation at ages above 70, while period conditions (proxied by period mortality at ages 0-15) explains a markedly smaller proportion of variation in old-age mortality. Crimmins and Finch also find that the early life mortality conditions explain more of the mortality variation for women than for men, possibly indicating that men are more robust to exposure to infection in early life. Using a similar data and methodological approach, Barbi and Vaupel (2005) make the argument that period conditions matter more than early life cohort conditions, but that both are important. These results, however, may be spurious as the majority of the variation in the independent and dependent variables is in the trends (see, for example, Hendry 1980).

One way to deal with the problem arising from trends is to do the analysis on de-trended variables. In demography, this approach was pioneered by Bengtsson and Lindström (2000, 2003), who analyze the association between deviation from trend in mortality at the time of birth and deviation from trend in old-age mortality. Bengtsson and Lindstöm de-trend by using the Hodrick-Prescott filter (Hodrick and Prescott 1997), which has become a common tool in demography (for example, van den Berg et al. 2009; Gagnon and Mazan 2009). Bengtsson and colleagues have used data from $18^{\text {th }}-19^{\text {th }}$ century Sweden to analyze whether mortality conditions early in life, taken as a proxy for exposure to 
disease, predict mortality in adulthood (Bengtsson and Lindstrom 2000, 2003; Bengtsson and Broström 2009). Bengtsson et al. use Cox proportional hazard models to estimate the effects of mortality deviations from trend early in life on adult mortality, and find that those born during times of high mortality have increased adult mortality. The magnitude of the effect is sizable; for example. in the 2009 paper analyzing mortality above age 55 for the 1766-1839 birth cohorts, those born in years with very high infant mortality (deviation from trend in the highest decile), face up to $43 \%$ higher old-age mortality than those born in times of lower infant mortality. Others who have used similar designs to Bengtsson et al., however, often fail to find links between being born in times of high mortality and later mortality (van den Berg, Lindeboom and Portrait 2006; van den Berg, Doblhammer and Christensen 2009; Gagnon and Mazan 2009). It is not known what explains these differences.

Catalano and Bruckner (2006) also use a de-trending approach to study the association between cohorts’ early life and later mortality. They use national level historical mortality data for Sweden, Denmark, and England and Wales. Instead of the Hodrick-Prescott filter, Catalano and Bruckner detrend the early and later life mortality variables using ARIMA (Auto Regressive Integrated Moving Average) models and find that higher than expected mortality during the first five years of life may decrease life expectancy at age 5 by as much as 1.75 years, and that the effect is stronger for men than for women. The result suggests that at the cohort-level early life conditions play an important role in determining later mortality. In a follow-up paper (Bruckner and Catalano 2009) the authors decompose the effects of early life conditions on later mortality by age, and find that the majority of the effect is attributable to increased mortality at young ages (below 20).

To summarize, the research concerning the links between mortality early in life, a proxy for the epidemiologic environment, and later mortality is inconclusive. The results in studies that find a strong association between cohorts’ mortality early in life and later mortality using aggregate national-level mortality data may be confounded by changing period conditions (Barbi and Vaupel 2005; Crimmins 
and Finch 2006a, 2006b; Finch and Crimmins 2004), and studies that remove the potentially confounding period effect using de-trending techniques have provided mixed results (Bruckner and Catalano 2009; Catalano and Bruckner 2006; van den Berg et al. 2006, 2009; Gagnon and Mazan 2009; Bengtsson and Broström 2009; Bengtsson and Lindstrom 2000, 2003).

This paper studies the relative importance of cohort-level early life conditions versus period conditions on cohorts' mortality. I study how variation in cohorts' mortality at a given age depends on cohorts' early life conditions and on period conditions using historical mortality time series for five European countries. To avoid identification problems often present in studies involving age, period and cohort, I use mortality rates as proxies for period and early life conditions instead of using years to indicate cohorts and periods. To avoid spuriousness potentially arising from the fact that all mortality rates have a downward trend, I de-trend the variables and analyze deviations from trend ("shocks"). More specifically, as the dependent variable I use the relative deviation from trend in age-specific mortality. The explanatory variables are based on cohort's own mortality early in life, and on period mortality. Early life cohort mortality shocks are defined as relative deviations from trend in the cohorts' mortality at ages 0 and 1-4. I measure shocks in period mortality as relative deviations from trend in period mortality at ages 0-4. Regressing the dependent variable, deviation from trend in cohort’s agespecific mortality, on the cohort and period mortality shocks allows me to answer the question "If, at a given age, a cohort had higher/lower mortality than what would be expected based on the surrounding cohorts, how well do the cohort's mortality experiences early in life explain this, and how well does period mortality conditions explain this effect?” 


\section{POTENTIAL MECHANISMS}

\section{Individual-level mechanisms}

While this study uses aggregate data that does not allow separating different physiological and individual-level mechanisms that link early life conditions to later life health, it is important to understand what these links could be. Early life factors influencing later health may be related to nutritional factors in utero (Barker 1995; Barker et al. 2002) and after birth (Eriksson et al. 1999; Gunnell et al. 1996), exposure to disease in utero (Almond 2006) and after birth (Case, Fertig and Paxson 2005), or broader socioeconomic conditions and deprivation early in life (Arnesen and Forsdahl 1985; Notkola et al. 1985). Though the discussion below treats these factors separately, these factors tend to co-occur.

The effect of early life nutrition on adult health may work through physiological and social factors. One of the critical systems affected by nutrition early in life is the immune system. Waaler (1984) shows that shorter individuals have excess adult mortality mostly due to cardiovascular disease, tuberculosis, and obstructive lung disease, all of which may depend on the functioning of the immune system. Alternative physiological hypotheses are based on the “programming” hypothesis of chronic diseases during gestation or early childhood (Barker 1995; Barker et al. 2002). According to this hypothesis, metabolic “programming” occurs at critical periods of early development and substantially determines health later in life. Eriksson et al. (1999; 2001) suggest that low birth weight (a proxy for in utero nutrition), followed by poor infant growth and rapid catch-up growth are associated with coronary heart disease, hypertension and type 2 diabetes. Low birth weight may also be associated with increased blood pressure in adulthood (Davies et al. 2006), though the magnitude of the effect may be small (Kramer 2000). Early life nutrition may also affect later health indirectly: through height and size, nutrition may be associated with productivity and adult socioeconomic status. 
Early disease exposure has been linked to current and historical major causes of death, such as respiratory tuberculosis, which can be latent in an individual for many years (Elo and Preston 1992), and cardiovascular disease, which may be attributable to chronically increased inflammation levels caused by early exposure to disease (Finch and Crimmins 2004; Mazumder et al. 2009). Early exposure to disease may also affect later life mortality indirectly through nutritional deprivation, which in turn may be related to adult health. Exposure to disease may also affect the ability to accumulate social and economic resources, leading to increased risk of death (Case et al. 2005). On the other hand, early exposure to disease may also improve later health. It is possible that for proper development of the immune system a certain amount of disease exposure is beneficial (Gurven et al. 2008), and some hypothesize that modern epidemics of allergies and asthma result from early life underexposure of the immune system (Folkerts, Walzl and Openshaw 2000; Holt 1995).

In addition to disease and nutrition, childhood socioeconomic environment may affect adult health through opportunities to accumulate socioeconomic resources, inherited social behavior and attitudes, and the links that childhood socioeconomic environment may have with early life nutrition and disease exposure (Kuh and Ben-Shlomo 2004). Socioeconomic environment, however, may not be very important for cohort-level mortality, as within-cohort position in the socioeconomic ladder may be more important than cross-cohort differences.

\section{Cohort-level mechanisms and anticipated effects}

The population-level effects of shocks in the epidemiologic environment may be different from the individual-level effects. In the period perspective, there is no confusion. The direction of the effect is almost certainly positive as any shock that increases mortality at one age is likely to increase mortality also at other ages for the same period. The direction of the effects in the cohort perspective, however, depends on how selection, scarring and immunity even out. ${ }^{2}$ 
First, a shock in a cohort's early life conditions may have a selective effect, killing the weakest. The influence on later cohort-level mortality is then negative, decreasing mortality. Second, the shock may have a scarring effect which increases the mortality of the surviving cohort. Third, the shock may induce immunity, lowering the mortality for the surviving cohort. Thus the effects of period shocks are anticipated to be positive (increase in period mortality at one age is associated with an increase in other ages), but the direction and relative magnitude of the effects of shocks in a cohort's early epidemiologic environment is uncertain. In the cohort perspective, it is also unclear at what ages mortality would be altered by a shock in the early life conditions. The results of this study will shed light on which of the three within-cohort effects dominates: selection, scarring, or immunity, and which matters more for adult- and old-age mortality: cohort or period conditions.

\section{DATA, VARIABLES AND METHODS}

\section{Data and variables}

I use time series data on the numbers of deaths and years of exposure for Denmark (cohorts born in 1835-1915), England and Wales (1841-1915), Finland (1878-1915), The Netherlands (1850-1915) and Sweden (1751-1915). The data quality for these countries is comparatively good. The data source is the Human Mortality Database (University of California, Berkeley (USA) and the Max Planck Institute for Demographic Research (Germany) 2008).

The dependent variable is derived from ${ }_{1} m_{x}(c)$, which represents the mortality rate at age $x$ for cohort $c$. As the explanatory variables I use shocks in cohorts' early life conditions and in period conditions. Shocks in cohorts' early life conditions are derived from the cohort's own mortality rates at ages 0 and 1-4, denoted by ${ }_{1} m_{0}(c)$ and ${ }_{4} m_{1}(c)$. Shocks in period mortality conditions are derived from period mortality at ages 0-4. 


\section{Methods}

To reduce heteroscedasticity, I transform the mortality rates to log-scale. I translate all the variables into deviations from trend in order to avoid the potential problem arising from unobserved factors driving the trends. In the decomposition to trend and deviation from trend, each series is de-trended over cohorts using the Hodrick-Prescott filter with smoothing parameter $\lambda=100$, a standard choice for annual data (Maravall and del Río 2007). Without de-trending, all the results would be mainly driven by the trends, potentially leading to spurious results.

Figure 1 shows selected variables (original series, estimated trend and relative deviation from trend) for Sweden, both sexes combined. Panel A shows the data for age 80. Relative deviation from trend in mortality at age 80 is one of the dependent variables; the analysis will be done for deviations from trend for all single-year age groups from 5 to 89 . Panel B shows period mortality rates at ages 0-4. Relative deviation in period mortality at ages $0-4$ is the period shock and is used to predict deviation from trend in mortality at higher ages. Panels $C$ and D show cohort mortality rates at ages 0 and 1-4. Relative deviations from trend in these rates are the shocks in cohorts' early life conditions and are used as the cohort predictors for mortality.

\section{FIGURE 1 ABOUT HERE}

Deviations from trend are based on log rates and represent relative short-term increases or decreases in mortality. For Sweden, one standard deviation (S.D.) shock in period mortality at ages 0-4, measured as the relative deviation from trend, corresponds to an $11 \%$ increase in mortality. For cohorts, the corresponding increases in mortality for a one S.D. shock are 5.6\% for infant mortality and $7.8 \%$ for mortality at ages 1-4. For other countries, one S.D. shocks in mortality rates are of similar magnitude to those of Sweden. ${ }^{3}$ 
Figure 2 illustrates how the cohort and period variables are matched with the dependent variable, relative deviation from trend in ${ }_{1} m_{x}(c)$ (mortality for cohort $c$ at age $x$ ). Figure 2 shows three cohorts progressing over time. The dependent variable is based on the cohort's mortality at age $x$, as shown in the figure (in the analysis $x$ runs from 5 to 89). For illustrative purposes, consider calculating the difference in the cohort mortality for cohort $c$ at age $x$ compared to the neighboring cohorts c- 1 and $c+1$ at the same age $x$. These mortality rates are shown in the top right circle of the graph. The obtained difference is the deviation from trend in mortality for cohort $c$ at age $x$ (in practice, the HodrickPrescott filter is used for de-trending, but the idea is the same).

Deviations from trend may be caused by the cohort’s early life conditions, period conditions, or something else such as chance. To study how the deviation from trend depends on the cohort's early life conditions and on the period conditions, I calculate the deviation from trend in the cohort's mortality at ages 0 and 1-4 (relevant mortality rates shown in the bottom left circle of the graph), and in period mortality at ages 0-4 (relevant mortality rates shown in the bottom right circle of the graph). Once these deviations from trend are obtained, the procedure is repeated for all cohorts. Finally, the deviation from trend in cohort mortality at age $x$ is regressed on deviations in the same cohort's mortality at ages 0 and 1-4, and on deviations in period mortality at ages $0-4$. Then the procedure is repeated for all ages from 5 to 89.

\section{FIGURE 2 ABOUT HERE}

Figure 3 illustrates the regression model. The model is estimated separately for each age $x=5,6, \ldots, 89$; thus there are 85 coefficients for both of the cohort variables (coefficient $\beta_{0, x}^{c}$ for infant mortality and $\beta_{1-4, x}^{c}$ for mortality at ages 1-4), and 85 coefficients for the period mortality variables (coefficient $\beta_{0-4, x}^{p}$ for period mortality at ages 0 -4). If the cohort shocks are positively correlated with 
later mortality $\left(\beta_{0, x}^{c}, \beta_{1-4, x}^{c}>0\right)$ for all or most ages $x$, then the scarring effect dominates the selection and immunity effects. If the cohort shocks are negatively correlated with later mortality $\left(\beta_{0, x}^{c}, \beta_{1-4, x}^{c}<0\right)$ for all or most ages $x$, then selection and immunity effects dominate. Finally, if the magnitude of the cohort coefficients is larger than the magnitude of the period coefficients, early life conditions may be more important in determining adult- and old-age mortality than period conditions, and vice versa.

\section{FIGURE 3 ABOUT HERE}

I estimate the cohort and period coefficients by regressing the dependent variable (deviation from trend in mortality) on the cohort and period variables. I control for the most dramatic period shocks of the observation window, the first and second World Wars (years 1914-1918 and 1939-1945, respectively) and the 1918 Spanish Influenza. I control for these exceptional period mortality shocks as they might otherwise dominate the period effects. I summarize the estimates graphically, plotting exponentiated coefficients $\exp (\beta)$ against age. The coefficients are standardized to reflect a one standard deviation increase in the independent variables. An exponentiated coefficient for cohort shock at age 0 tells us how much, in proportional terms, the cohort's mortality at a given age increases or decreases for a one S.D. shock in log mortality at age 0 . The coefficients for the cohort shocks at ages 1-4 and for the period shocks at ages 0-4 are interpreted analogously. The Appendix provides further details on the model, including a discussion on whether the effects for infant and child mortality should be estimated jointly or separately. Here we present results for a model that estimates the effects simultaneously, as the results do not change if these effects are estimated separately. The finding that these effects can be estimated simultaneously is consistent with earlier research (Myrskylä 2010).

To appreciate the differences in the magnitude between the effects for the cohort and period shocks, I express the effects also in terms of life expectancy. I calculate the change in life expectancy at age 5 for standardized shocks in cohorts' mortality at ages 0 and 1-4 and for standardized shocks in 
period mortality at ages 0-4. I use country-specific 1900 cohort life tables as the basis for this calculation. The cohort life tables are used for both cohort and period shocks in order to keep the effects comparable. The effect of a standardized shock in cohorts' mortality at age 0 on life expectancy at age 5 is calculated by first multiplying the original age-specific mortality rates by the estimated coefficients $\beta_{0, x}^{c}$ and then comparing the resulting life expectancy at age 5 to the original life expectancy at age 5 . The effects for shocks in cohort mortality at ages 1-4 and in period mortality at age 0-4 are calculated analogously, using the coefficients $\beta_{1-4, x}^{c}$ and $\beta_{0-4, x}^{p}$. I decompose the effect on life expectancy to juvenile and young adult ages (5-19), adult ages (20-59), and old ages (60-89), and average the effects over the five countries.

\section{RESULTS}

The results are in three sections. The first section focuses on Sweden and England and Wales. These countries are covered in more detail because the patterns for Denmark, Finland and The Netherlands are very close to those of Sweden, and because the results for Sweden and England and Wales show interesting contrasts. The second section covers all of the five countries. The third section discusses potential gender differences.

\section{Sweden and England and Wales}

Figure 4 shows the effects of shocks in early life cohort and later life period conditions, measured from cohort mortality at ages 0 and 1-4 and from period mortality at ages 0-4 (Panel A: Sweden, Panel B: England and Wales). The dots in Figure 4 are exponentiated coefficients $\exp (\beta)$ and are interpreted as hazard ratios for one standard deviation (S.D.) shock; the lines are locally weighted smoothed regression curves (lowess) fitted to $\exp (\beta)$. We can interpret these values as follows. Suppose there is an estimate of 1.02 at age 80 for a shock in cohort's infant mortality $\left(1.02=\exp \left(\beta_{0,80}^{c}\right)\right)$. This means 
that one S.D. shock in the cohort's log mortality at age 0 is associated with a $2 \%$ increase in the same cohort's mortality at age 80. Coefficients for other cohort shocks are interpreted analogously. Similarly, for the period mortality shocks, an estimate of 1.05 for age 80 means that a one S.D. shock period mortality at ages $0-4$ is associated with a $5 \%$ increase in mortality at age 80 for the same period. For other ages, the interpretation is the same.

\section{FIGURE 4 ABOUT HERE}

Consider first the effects of the cohort shocks. For both Sweden and England and Wales, the hazard ratios for shocks measured at age 0 are close to 1 for all ages. When the coefficients for Sweden are applied to the Swedish 1900 cohort life table, a one S.D. shock in infant mortality results in 0.4 months reduction in life expectancy at age 5. For England and Wales, the effect of a shock in infant mortality is slightly above 1.00 between ages 25 and 75, converging to 1 at the oldest ages. When applied to the 1900 England and Wales cohort life table, this increased mortality due to a one S.D. shock corresponds to 0.5 months’ reduction in life expectancy at age 5. Based on the Swedish coefficients, a three S.D. shock would correspond to a 1.2 months decrease in life expectancy in Sweden and 1.5 months in England and Wales and slightly less in Sweden. In general, these effects are not large.

The effects of shocks in mortality at ages 1-4 are also small. For Sweden, the hazard ratios are slightly below 1 at ages 5-20, but converge to 1 at older ages. Thus if a cohort had above-average mortality at ages 1-4, it will have a below-average mortality at ages 5-20. This result is consistent with theories of selection. For all cohorts, mortality is very low at ages 5-20. Those few who die at these ages may be very frail (wartimes, and accident mortality may constitute exceptions). If mortality at ages 1-4 is above average, this mortality shock may selectively affect those who otherwise would have lived to age 5 but died at relatively young ages. An alternative explanation is acquired immunity, 
wherein those who survive the event that increases mortality at ages 1-4 acquire immunity for similar events later in life. In this study, however, it is not possible to distinguish between these theories. Whichever mechanism is responsible for the inverse link between mortality at ages 1-4 and 5-20, the effect is not particularly strong, corresponding to 0.3 months of increased life expectancy at ages 5-20 for a one S.D. shock, and 0.8 months for a three S.D. shock. Furthermore, while the effect is present in Finland, the Netherlands, and Denmark (more on these country comparisons in the next section), the effect is not observed in England and Wales. In summary, the cohort coefficients look relatively small. While some individual hazard ratios for cohort shocks may be as high as 1.03-1.04, the lowess curves show that overall, shocks in cohorts' mortality at ages below 5 have only little effect on later mortality.

Next consider the period coefficients. For both Sweden and England and Wales, these are always above 1.00, which is expected. If mortality increases at young ages, it is likely that mortality increases also at older ages. In relative terms, the effects of the period mortality shocks dominate the cohort shock effects. In Sweden, one S.D. shock in period mortality at ages 0-4 is associated with 8 months decrease in life expectancy at age 5, and 6 month decrease in England and Wales. For a 3 S.D. shock the corresponding decrease in life expectancy is 23 months Sweden and 19 months for England and Wales.

\section{All countries}

Figure 5 shows the effects for cohort and period shocks by country. The results in Figure 5 are grouped so that Panel A shows the effects of cohort shocks at age 0, Panel B shows the effects of cohort shocks at ages 1-4, and Panel $\mathrm{C}$ is for period shocks measured at ages $0-4 .^{4}$

\section{FIGURE 5 ABOUT HERE}


Panels A and B confirm what Figure 4 suggested. In all countries, cohort shocks have only little influence on later mortality. Panel A shows that cohort shocks measured from infant mortality seem to have only little effect on later mortality. Cohort shocks experienced in early childhood (ages 1-4; Panel B) decrease mortality at ages 5-20, but the effect is small: In the Netherlands, Finland, Denmark and Sweden, mortality at ages 5-20 is reduced by approximately 1-2 \% for a one S.D. shock at ages 1-4.

Panel C shows the effects of period shocks. All countries show a similar pattern: high period mortality at ages 0-4 is correlated with high period mortality at older ages. In proportional terms the period association between mortality at ages 0-4 and older age mortality gets weaker over age. However, mortality increases over age at a faster rate than the coefficients shown in Figure 5c decline, so in terms of absolute mortality the period associations do not weaken over age. In fact, in absolute terms the period relationship between shocks in mortality at ages 0-4 and mortality at older ages resembles the almost universal pattern of human mortality, decreasing up to ages 10-15 and then increasing (these results not shown).

To appreciate the differences in the magnitude of the cohort and period effects, it is useful to look at the effects in terms of life expectancy. Figure 6 shows the effects of 3 S.D. shocks in cohorts’ infant mortality, child mortality, and period mortality on life expectancy at ages 5-89. The estimates are based on the coefficients shown in Figure 5 and country-specific cohort life tables for year 1900. The effects are decomposed into effects at juvenile and young adult ages (5-19), adult ages (20-59), and old ages (60-89), and averaged over the five countries. Figure 6 shows that on average, the effect of a shock in cohort mortality at age 0 on life expectancy at ages 5-89 is negative. A 3 S.D. shock results in 0.5 months' reduced life expectancy. ${ }^{5}$ The majority of the averaged effect (-0.3 months) is attributable to ages 5-19. At age 20-59 the effect is less than 0.1 months, and at ages $60-89$ the effect is -0.2 months. For shocks in cohort mortality at ages 1-4 the net effect is positive, increasing life expectancy 
at ages 5-89 by 0.2 months. This positive effect is attributable to ages 5-19 (+0.6 months). At ages 2059 the effect is negligible, and at old ages (60-89) -0.3 for 3 S.D. shock.

\section{FIGURE 6 ABOUT HERE}

A 3 S.D. shock in period mortality at ages 0-4, in turn, is associated with a decrease in life expectancy of about 8.7, 8.4 and 3.6 months at ages 5-19, 20-89 and 60-89, respectively. The net effect over the whole age range, 5-89, is -20.6 months for a 3 S.D. shock. In comparison to period shock effects, the impact of shocks in a cohort's early life conditions on later life mortality seems modest.

\section{SENSITIVITY CHECKS}

I studied whether the results would differ by sex by replicating all the analyses separately for men and women. The results were highly similar for both sexes. I also studied the sensitivity of the results with respect to the de-trending technique, the regression models, and the time period for which the effects were estimated. This study used the Hodrick-Prescott filter with smoothing parameter $\lambda=100$. Alternative smoothing parameters $\lambda=6.25$ (suggested by Ravn and Uhlig (2002) for annual data) and $\lambda=1600$ (often used for quarterly data) changed the magnitude of the deviations from trend but not the estimates for the model parameters. In addition, differencing instead of using the Hodrick-Prescott filter to de-trend the data did not change the results. Second, I studied the sensitivity of the results to the autocorrelation structure of the regression model. The results shown in here were obtained by having no autocorrelation in the models. Allowing autocorrelation with lags up to 3 did not change the results. Third, I estimated the models for the period preceding secular declines in mortality. Among the countries studied, only Sweden has observations for the period preceding mortality decline. Mortality was approximately stationary (and data available) in years 1751-1810. The results for this period were consistent with the results obtained when using cohorts up to 1915. Fourth, I estimated the models for the period when life expectancy at birth was below 50 (for Denmark, cohorts 1835-1870, England and 
Wales 1841-1879, Finland 1887-1905, The Netherlands 1850-1886 and Sweden 1751-1877). The results for these cohorts were similar to what they were for the full data. Fifth, I estimated the models using data for only the most extreme years by including only the observations for which infant mortality shock was in the top or bottom quintile of the distribution. Again, the results did not change. Finally, I estimated the models using absolute deviations from trend, instead of relative deviations. The results did not change.

\section{DISCUSSION}

This study analyzes the relative importance of cohorts' early life conditions versus period conditions on mortality by simultaneously estimating early life cohort effects and period effects. Using historical mortality data for Denmark, England and Wales, Finland, The Netherlands and Sweden I found that shocks in early life conditions, proxied by cohorts’ own infant mortality, are only weakly associated with cohorts' later mortality. In the cohort perspective, shocks in infancy (defined as relative deviations from trend in infant mortality), are associated with increased mortality at ages 5-20 and above 60, suggesting scarring. The magnitude of these effects, however, is small. Shocks at ages 1-4 are inversely, but not particularly strongly, associated with mortality at ages 5-20; at older ages this association vanishes. Period mortality shocks, defined as deviations from trend in period mortality at

ages 0 -4, were positively and strongly correlated with mortality at all ages between 5 and 89 years so that a shock that increases mortality at young ages increases mortality also at older ages. In comparison to the effects of shocks in cohorts' early life conditions, shocks in period conditions had a much stronger influence on mortality.

The finding that shocks in cohorts' conditions during the first year of life are associated with old-age mortality (though only weakly) suggests that early life events may have an impact on mortality decades later through scarring. The finding that high mortality at ages 1-4 may decrease mortality at 
ages up to 20 may be due to selection or acquired immunity. For all cohorts, mortality is at its lowest at ages 5-20. Those who die at these ages are likely to be very frail. If mortality at ages 1-4 happens to be above-average, this excess mortality may act selectively on who otherwise would have lived to age 5 but died at relatively young ages. Alternatively, or in addition, acquired immunity may also be responsible for the effect. In this study, however, it was not possible to separate these two mechanisms.

Men and women responded similarly to period and cohort shocks, and overall, gender differences were small. Theories to explain why one of the sexes would be more robust to harmful early life conditions are plentiful, but the empirical evidence is mixed (Catalano and Bruckner 2006; Crimmins and Finch 2006a; van den Berg, Lindeboom and Portrait 2007). A tentative conclusion is that there are no strong differences between the two sexes in their response to shocks in early life conditions.

In summary, our analyses point to four main results: small increase or no effect at all in mortality for cohorts which had above-trend mortality at infancy, slightly decreased mortality up to age 20 for cohorts which had above-trend mortality in early childhood, slightly increased old-age mortality for the cohorts which had high infant and child mortality, and very strong period dependencies in mortality across all ages. These results apply most clearly to four of the countries analyzed: Denmark, Finland, The Netherlands and Sweden. England and Wales appears to be an outlier, showing no evidence of decreased mortality at ages 5-20 for cohorts which had unexpectedly high mortality at ages 1-4. There are several potential explanations why England and Wales looks different. First, the historical data for these countries may be of lower quality than for the other countries (Wrigley and Schofield 1981). Second, World War I and the 1918 Spanish influenza outbreak increased mortality in England and Wales so that for cohorts born between 1880 and 1895 life expectancy stalled or even declined. ${ }^{6}$ While other countries also suffered from the 1918 Spanish influenza, the toll of World War I was higher for England and Wales than it was for any other country analyzed in this study. These 
events caused disturbances in the mortality dynamics and may have affected the results. In previous research the disturbances of World War I on cohort mortality patterns have been well documented (Winter 1976) Derrick (1927; cited in Winter 1976) even claimed that, “[in England and Wales] the effects of losses during the European War were so great and indefinite as to obscure all normal changes.”

Some previous research has suggested that early life conditions may be more important than period conditions for old-age mortality (Finch and Crimmins 2004), or that, even if period conditions are more important, early life conditions proxied by the cohort's own early mortality could still have an important role (Barbi and Vaupel 2005). This study adds to the accumulating evidence suggesting that at the cohort-level, early life mortality conditions may not be an important predictor of adult- and oldage mortality (Bruckner and Catalano 2009; Gagnon and Mazan 2009; van den Berg, Doblhammer and Christensen 2009). The findings of this study are also consistent with Murphy (2010), who finds that period factors may be more important than cohort factors in determining mortality. The results are also consistent with the studies finding no increased mortality among those who survived great famines as young children (Kannisto et al. 1997; Painter et al. 2005) or were exposed to disease in utero or during first year of life (Cohen, Tillinghast and Canudas-Romo 2010).

It is possible that some of the inconsistencies in the literature are caused by methodological differences. The major difference in the study designs between the current paper and those of Finch and Crimmins (2004) and Barbi and Vaupel (2005), who both find evidence for early life conditions strongly predicting later cohort mortality, is that the current study de-trended the mortality time series before analysis. This de-trending may importantly influence the results, as without de-trending the observed correlations are potentially biased by unobserved factors driving the trends (Hendry 1980). De-trending, however, comes with a cost: while analysis of de-trended time series allows better identification of the regression parameters, the external validity of the estimated parameters may 
decrease. In other words, it may be that the effects that are estimated for deviations from trends do not fully correspond to the effects of long-term secular changes in early life conditions. If the factors that increased or decreased mortality in the short term are very different from the factors that influenced the secular trends in mortality decline, one may not be able to generalize the parameters representing the effects for deviations from trend to represent the effects for secular changes in early life conditions. The majority of short term variation in mortality in the $18^{\text {th }}-19^{\text {th }}$ centuries was attributable to infectious diseases and epidemic outbursts. Decline in infectious diseases and epidemics were also important factors driving the secular decline in mortality in the $18^{\text {th }}-20^{\text {th }}$ centuries. Therefore it seems reasonable to generalize the effects based on short term variation to represent the effects of secular changes.

Nevertheless, the studies showing negative effects on other than mortality outcomes (Almond 2006; Mazumder et al. 2009) and studies which find mortality effects for those born during times of adverse early life conditions (van den Berg et al. 2006; Bengtsson and Brostrom 2009) suggest that early life conditions do matter for later life outcomes. It is possible that early life conditions are important for cohorts' later life mortality, but early life mortality conditions generally do not capture the important aspects of early life conditions. For example, van den Berg and colleagues (van den Berg, Lindeboom and Portrait 2006; van den Berg, Doblhammer-Reiter and Christensen 2008; van den Berg et al. 2009) find that early life macroeconomic conditions predict cohorts' later mortality: being born in a recession increases later mortality. Cutler et al. (2007), however, focusing on the effect of the 1930s Depression, do not find any health effects for later life for those born during the depression. Portrait et al. (2010) analyze the effects of macroeconomic conditions early in life on later life health among Dutch cohorts born in 1909-1937 and get similar results: early life macroeconomic conditions do not explain later life health, but later life period conditions do. These findings mirror the results of this paper, and suggest that while early life macroeconomic conditions may have been an important 
predictor for later health in historical periods, the association may have weakened over time as nutrition has become more plentiful and exposure to disease less frequent and severe.

Despite the inconsistencies with some of the prior research, the findings of this study have implications for the understanding of mortality declines and old-age mortality. This study did not find important links between cohorts’ early and old-age mortality, but did find strong period dependencies in mortality rates. This indicates that the majority of cohort differences in mortality are explained by factors other than early life conditions, and that declines, or more generally changes, in cohort-level old-age mortality may be driven by changes in period conditions rather than changes in early life conditions. While a full discussion on what these period factors are is beyond the scope of this paper, it is possible to briefly discuss some of the potentially more important factors. As discussed in Vallin and Meslé (2009), mortality started to improve in the late $18^{\text {th }}$ to early $19^{\text {th }}$ centuries. This change coincided with rapid developments in food production and the adoption of Jenner's smallpox vaccine. In the $19^{\text {th }}$ century, continued improvements in nutrition and sanitation, and the revolution in the understanding of the nature and diffusion of disease (the "germ theory of disease”) were important period-based factors driving mortality change. In the late $19^{\text {th }}$ and early $20^{\text {th }}$ centuries the spread of clean water technologies has decreased mortality in a largely period-based manner (Cutler and Miller 2005), and in the latter half of the twentieth century decreases in smoking (Preston and Wang 2006) and development of effective medical technologies, especially in prevention and treatment of cardiovascular diseases(Vallin and Meslé 2004), have influenced the mortality decline.

The results of this paper show that period conditions dominate mortality variation, and suggest that the secular trends may be more attributable to changing period rather than early life conditions. The results, however, should not be interpreted as refuting the several well-designed studies that have found evidence for cohort patterns in mortality or for long-lasting negative effects for early life adverse conditions. For example, respiratory tuberculosis acquired early in life can be latent in an individual for 
many years giving rise to lagged effects from early to late life (Des Prez and Goodwin 1985); differences in cohort smoking patterns cause cohort differences in mortality (Preston and Wang 2006); and those exposed to the 1918 Pandemic in utero have excess heart disease prevalence when compared to the surrounding cohorts (Mazumder et al. 2009). In fact, the findings of the current study, showing small scarring effects for those born during times of high infant mortality, are consistent with the literature suggesting that old-age mortality is partially dependent on early life conditions. This paper, however, puts the magnitude of the early life effects into perspective and compares them to the period effects. In this comparison, the importance of early life conditions on later life mortality seems modest, as the variation in mortality rates is driven almost exclusively by period conditions. 


\section{Appendix: Model details}

The model that I use to estimate the cohort coefficients $\beta_{0, x}^{c}$ and $\beta_{1-4, x}^{c}$ and the period coefficients $\beta_{0-4, x}^{p}$ for each age $x=5,6, \ldots, 89$ is of the form

$$
Y_{x}=\boldsymbol{\beta}_{x}^{\prime} \mathbf{X}_{x}+\gamma^{\prime} \text { Controls }+\varepsilon_{x},
$$

where $Y_{x}$ is the dependent variable (relative deviation from trend in mortality at age $x$ ); $\mathbf{X}_{x}$ is the vector of cohort and period variables (cohort variables: relative deviations from trend in cohort's mortality at ages 0 and 1-4; period variable: relative deviation from trend in period mortality at ages 0 -

4); Controls is a vector which has dummies that capture the effects of the most dramatic period shocks of the observation window, the first and second World Wars (years 1914-1918 and 1939-1945, respectively) and the 1918 Spanish Influenza. I control for these exceptional period shocks as they might otherwise dominate the period effects. Without these controls, the period effects would be slightly larger. The model does not include intercepts as all de-trended variables have a zero mean. I estimate the model using ordinary least squares.

Model (1), when estimated for both sexes and by sex produces 3,825 estimates, 85(age) x 4(2 cohort +1 period coefficient) $\times$ 3(both genders, men, women) x 5(countries). I summarize the estimates graphically, plotting exponentiated coefficients $\exp (\beta)$ against age. The coefficients are standardized to reflect a one standard deviation increase in the independent variables. An exponentiated coefficient for cohort shock at age 0 tells us how much, in proportional terms, the cohort's mortality at a given age increases or decreases for a one standard deviation shock in log mortality at age 0 . The coefficients for the cohort shocks at ages 1-4 and for the period shocks at ages 0-4 are interpreted analogously.

To study the robustness of the results observed with Model (1), I estimated several alternative model specifications. The Model (1) includes cohort shocks at ages 0 and 1-4 and period shocks at ages 
$0-4$. With this specification the target parameter vector is $\boldsymbol{\beta}_{x}=\left(\beta_{0, x}^{c}, \beta_{1-4, x}^{c}, \beta_{0-4, x}^{p}\right)$. Shocks in infant and child mortality, however, may be so highly correlated that joint estimation of the effects $\beta_{0, x}^{c}, \beta_{1-4, x}^{c}$ is inaccurate. Therefore I estimated two complementing alternative models in which the two cohort coefficients were estimated separately, not simultaneously. The results were only marginally different from those obtained with Model (1). In addition, I estimated the models without control for period effects. Again, the results changed only marginally. Therefore, only results for Model (1) are shown.

To ensure that the results are robust to how the cohort and period shocks were defined, I estimated the effects using alternative definitions of cohort and period shocks. First, I replaced the cohort shocks by the deviation from trend in the Lee-Carter mortality index $k$ (Lee and Carter 1992) at the year of birth. The results did not change in any significant manner. Second, I tried alternative specifications of the period effect. When estimating the period effects for cohort $c$ at age $x$, I used the surrounding cohort's mortality at neighboring ages as the basis for the period shock. More specifically, I used two older and two younger cohorts as the surrounding cohorts. Thus for cohort $c$ at age $x$ I based the period shock on the combined mortality rate of cohorts $c+x-2, c+x-1, c+x+1$, and $c+x+2$ at ages $x+2, x+1, x-1, x-2$ and, respectively. The results for period effects were similar to what was observed with Model (1). In addition, I used the Lee-Carter mortality index $k$ as the basis for period shocks (matched with the year and cohort). Again, the results changed only marginally when compared to Model (1). 


\section{REREFENCES}

Human Mortality Database 2008. University of California, Berkeley (USA) and Max Planck Institute for Demographic Research (Germany).Available online at www.mortality.org.

Almond, D. 2006. "Is the 1918 Influenza Pandemic Over? Long-Term Effects of In Utero Influenza Exposure in the Post-1940 U.S. Population." Journal of Political Economy 114(4):672-712.

Arnesen, E.and A. Forsdahl. 1985. "The Tromso heart study: Coronary risk factors and their association with living conditions during childhood." Journal of Epidemiology and Community Health 39:210-214.

Barbi, E.and J.W. Vaupel. 2005. "Comment on "Inflammatory exposure and historical changes in human lifespans"." Science 308(5729):1743; author reply 1743.

Barker, D.J. 1995. "Fetal origins of coronary heart disease." British Medical Journal 311:171-174.

Barker, D.J., J.G. Eriksson, T. Forsen, and C. Osmond. 2002. "Fetal origins of adult disease: strength of effects and biological basis." Int J Epidemiol 31(6):1235-1239.

Bengtsson, T.and G. Broström. 2009. "Do conditions in early life affect old-age mortality directly and indirectly? Evidence from 19th-century rural Sweden." Social Science \& Medicine 68(9):1583-1590.

Bengtsson, T.and M. Lindstrom. 2000. "Childhood misery and disease in later life: the effects on mortality in old age of hazards experienced in early life, southern Sweden, 1760-1894." Popul Stud (Camb) 54(3):263-277.

—. 2003. "Airborne infectious diseases during infancy and mortality in later life in southern Sweden, 17661894." Int J Epidemiol. 32(2):286-294.

Bengtsson, T.and G.P. Mineau. 2009. "Early-life effects on socio-economic performance and mortality in later life: A full life-course approach using contemporary and historical sources." Social Science \& Medicine 68(9):1561-1564.

Bruckner, T.A.and R.A. Catalano. 2009. "Infant mortality and diminished entelechy in three European countries." Social Science \& Medicine 68(9):1561-1564

Case, A., A. Fertig, and C. Paxson. 2005. "The Lasting Impact of Childhood Health and Circumstance." Journal of Health Economics 24(2):365-389.

Catalano, R.and T. Bruckner. 2006. "Child mortality and cohort lifespan: a test of diminished entelechy." Int $J$ Epidemiol 35(5):1264-1269.

Cohen, A., J. Tillinghast, and V. Canudas-Romo. 2010. "No consistent effects of prenatal or neonatal exposure to Spanish flu on late-life mortality in 24 developed countries." Demographic Research 22(20):579-634.

Costa, D.L.and J.N. Lahey. 2005. "Predicting older age mortality trends." Journal of the European Economic Association 3(2-3):487-493.

Crimmins, E.M.and C.E. Finch. 2006a. "Commentary: Do older men and women gain equally from improving childhood conditions?" Int J Epidemiol. 35(5):1270-1271.

—. 2006b. "Infection, inflammation, height, and longevity." Proc Natl Acad Sci U S A 103(2):498-503. 
Cutler, D.M.and G. Miller. 2005. "The Role of Public Health Improvements in Health Advances: The TwentiethCentury United States " Demography 42(1):1-22.

Cutler, D.M., G. Miller, and D.M. Norton. 2007. "Evidence on early-life income and late-life health from America's Dust Bowl era." Proceedings of the National Academy of Sciences 104:13244-13249.

Davies, A.A., G. Davey Smith, M.T. May, and Y. Ben-Shlomo. 2006. "Association between birth weight and blood pressure is robust, amplifies with age, and may be underestimated." Hypertension. 48:431-436.

Derrick, V.P.A. 1927. "Observations on (1) errors in age in the population statistics of England and Wales, and (2) the changes in mortality indicated by the national records." Journal of the Institute of Actuaries 58:117-159.

Des Prez, R.M.and R.A.J. Goodwin. 1985. "Mycobacterium tuberculosis." in Principles and Practice of Infectious Diseases. 2nd ed., edited by G.L. Mandell, R.G. Douglas Jr., and J.E. Bennett. New York: Churchill Livingstone.

Elo, I.T.and S.H. Preston. 1992. "Effects of early-life conditions on adult mortality: a review." Popul Index 58(2):186-212.

Eriksson, J.G., T. Forsen, J. Tuomilehto, C. Osmond, D.J. Barker, C. Osmond, D.J. Barker, P.D. Winter, C.H. Fall, and S.J. Simmonds. 2001. "Early growth and coronary heart disease in later life: longitudinal study." BMJ 322(7292):949-953.

Eriksson, J.G., T. Forsen, J. Tuomilehto, P.D. Winter, C. Osmond, and D.J. Barker. 1999. "Catch-up growth in childhood and death from coronary heart disease: longitudinal study." British Medical Journal 318(7181):427431.

Finch, C.E.and E.M. Crimmins. 2004. "Inflammatory exposure and historical changes in human life-spans." Science 305(5691):1736-1739.

Fogel, R.W. 2004. The Escape from Hunger and Premature Death, 1700-2100: Europe, America, and the Third World. New York: Cambridge University Press.

Folkerts, G., G. Walzl, and P.J.M. Openshaw. 2000. "Do common childhood infections 'teach' the immune system not to be allergic?" Immunology Today 31:118-120.

Gagnon, A.and R. Mazan. 2009. "Does exposure to infectious diseases in infancy affect old-age mortality? Evidence from a pre-industrial population." Social Science \& Medicine 68(9):1609-1616.

Gunnell, D.J., S. Frankel, K. Nanchahal, F.E.M. Braddon, and G. Davey Smith. 1996. "Lifecourse exposure and later disease: a follow-up study based on a survey of family diet and health in pre-war Britain (1937-1939). ." Public Health 110:85-94.

Gurven, M., H. Kaplan, J. Winking, C.E. Finch, and E.M. Crimmins. 2008. "Aging and Inflammation in Two Epidemiological Worlds." The Journals of Gerontology 63A:196-199.

Hayward, M.D.and B.K. Gorman. 2004. "The long arm of childhood: The influence of early-life social conditions on men's mortality." Demography 41 87-107.

Hendry, D.F. 1980. "Econometrics-Alchemy or Science?" Economica 47(188):387-406.

Hodrick, R.J.and E.C. Prescott. 1997. "Postwar U.S. Business Cycles: An Empirical Investigation." Journal of Money, Credit and Banking 29(1):1-16. 
Holt, P.G. 1995. "Postnatal maturation of immune competence during infancy and childhood." Pediatric Allergy and Immunology 6:59-70.

Kannisto, V., K. Christensen, and J.W. Vaupel. 1997. "No increased mortality in later life for cohorts born during famine." Am J Epidemiol 145(11):987-994.

Kermack, W.O., A.G. McKendrick, and P.L. McKinlay. 1934. "Death rates in Great Britain and Sweden: Some general regularities and their significance." Lancet 226(698-703).

—. 2001. "Death-rates in Great Britain and Sweden. Some general regularities and their significance." Int $J$ Epidemiol. 30(4):678-683.

Kramer, M.S. 2000. "Invited commentary. Association between restricted fetal growth and adult chronic disease: Is it causal? Is it important?" American Journal of Epidemiology 152:605-608.

Kuh, D.and Y. Ben-Shlomo. 2004. "A Life course approach to chronic disease epidemiology." Oxford: Oxford University Press.

Lee, R.D.and L.R. Carter. 1992. "Modeling and Forecasting U. S. Mortality." Journal of the American Statistical Association 87(419):659-671.

Maravall, A.and A. del Río 2007. "Temporal aggregation, systematic sampling, and the Hodrick-Prescott filter." in Bank of Spain Documents de Trabajo.

Mazumder, B., D. Almond, K. Park, E.M. Crimmins, and C.E. Finch. 2009. "Lingering prenatal effects of the 1918 influenza pandemic on cardiovascular disease." Journal of Developmental Origins of Health and Disease.

Murphy, M. 2010. "Reexamining the Dominance of Birth Cohort Effects on Mortality." Population and Development Review 36(2):365-390.

Myrskylä, M. 2010. "The effects of shocks in early life mortality on later life expectancy and mortality compression: A cohort analysis." Demographic Research 22(12):289-320.

Notkola, V., S. Punsar, M.J. Karvonen, and J. Haapakoski. 1985. "Socio-economic conditions in childhood and mortality and morbidity caused by coronary heart disease in adulthood in rural Finland." Social Science and Medicine 21:517-523.

Oeppen, J.and J. Vaupel. 2002. "Broken limits to life expectancy." Science 296:1029-1031.

Painter, R.C., T.J. Roseboom, P.M. Bossuyt, C. Osmond, D.J. Barker, and O.P. Bleker. 2005. "Adult mortality at age 57 after prenatal exposure to the Dutch famine." Eur J Epidemiol. 20(8):673-676.

Portrait, F., R. Alessie, and D. Deeg. 2010. "Do early life and contemporaneous macroconditions explain health at older ages? An application to functional limitations of Dutch older individuals." Journal of Population Economics 23:617-642.

Preston, S.H., M.E. Hill, and G.L. Drevenstedt. 1998. "Childhood conditions that predict survival to advanced ages among African-Americans." Soc Sci Med 47(9):1231-1246.

Preston, S.H.and E. van de Walle. 1978. "Urban French Mortality in the Nineteenth Century." Population Studies 32(2):275-297.

Preston, S.H.and H. Wang. 2006. "Sex Mortality Differences in the United States: The Role of Cohort Smoking Patterns." Demography 43(4):631-646. 
Ravn, M.O.and H. Uhlig. 2002. "On Adjusting the Hodrick-Prescott Filter for the Frequency of Observations." The Review of Economics and Statistics 84(2):371-376.

Vallin, J.and F. Meslé. 2004. "Convergences and divergences in mortality: A new approach to health transition " Demographic Research Special Collection 2, article 2, :11-43.

van den Berg, G., M. Lindeboom, and F. Portrait. 2006. "Economic Conditions Early in Life and Individual Mortality." American Economic Review 96(1):290-302.

van den Berg, G.J., G. Doblhammer-Reiter, and K. Christensen. 2008. "Being Born Under Adverse Economic Conditions Leads to a Higher Cardiovascular Mortality Rate Later in Life: Evidence Based on Individuals Born at Different Stages of the Business Cycle." IZA Discussion Paper No. 3635.

van den Berg, G.J., G. Doblhammer, and K. Christensen. 2009. "Exogenous determinants of early-life conditions, and mortality later in life." Social Science \& Medicine 68(9):1591-1598.

van den Berg, G.J., M. Lindeboom, and F. Portrait. 2007. "Long-Run Longevity Effects of a Nutritional Shock Early in Life: The Dutch Potato Famine of 1846-1847." IZA Discussion Paper No. 3123

Waaler, H. 1984. "Height, weight, and mortality: the Norwegian experience." Acta Medica Scandicana (Supplement) 679:1-56.

Wilmoth, J., J. Vallin, and G. Caselli. 1990. "When Does a Cohort's Mortality Differ from What we Might Expect?" Population: An English Selection 2:93-126.

Winter, J.M. 1976. "Some Aspects of the Demographic Consequences of the First World War in Britain." Population Studies 30(3):539-552.

Wrigley, E.A.and R.S. Schofield. 1981. The Population History of England, 1541-1871: A Reconstruction. Cambridge: Harvard University Press. 
Figure 1. Sweden, selected mortality time series, both sexes combined. Panel A: Mortality at age 80 by birth cohort; Panel B: Mortality at ages $0-4$ by period; Panel C: Mortality at age 0 by birth cohort; Panel D: Mortality at ages 1-4 by birth cohort. Source: Observations Human Mortality Database; trend and residuals own calculations. Left vertical axis: mortality rates on the log scale. Right vertical axis: Relative deviation from trend.

A. Mortality at age 80 by cohort

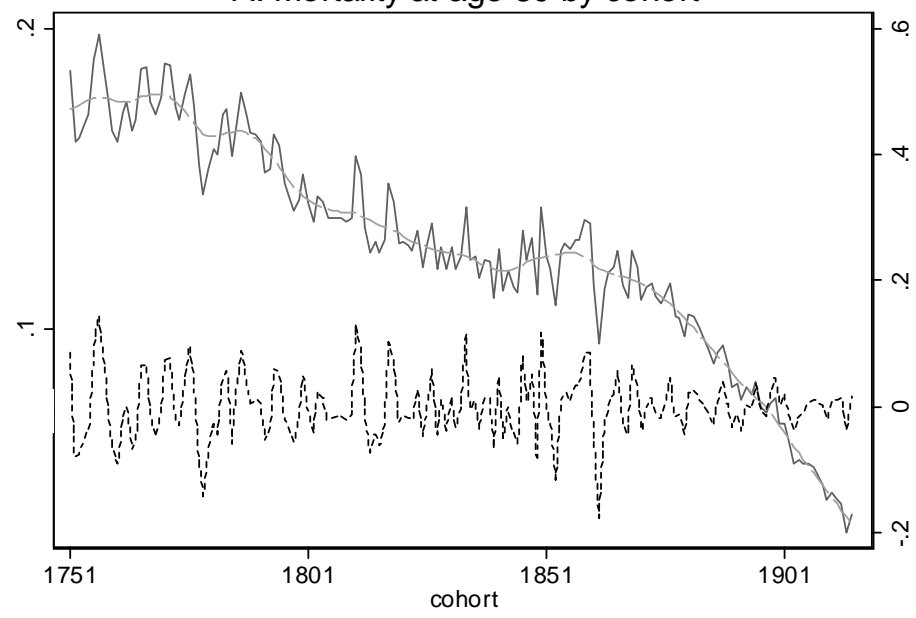

C. Mortality at age 0 by cohort

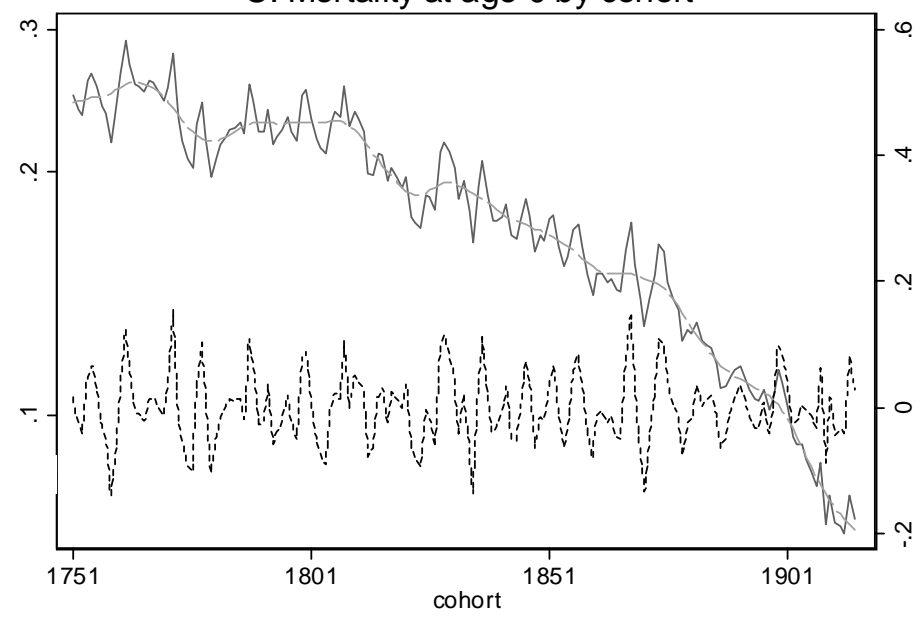

B. Mortality at ages $0-4$ by period

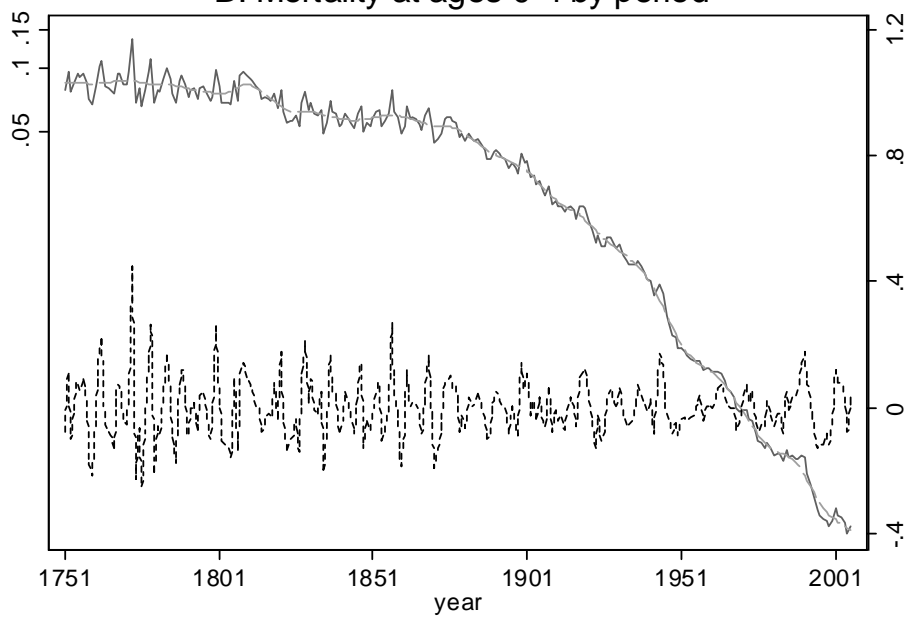

D. Mortality at ages $1-4$ by cohort

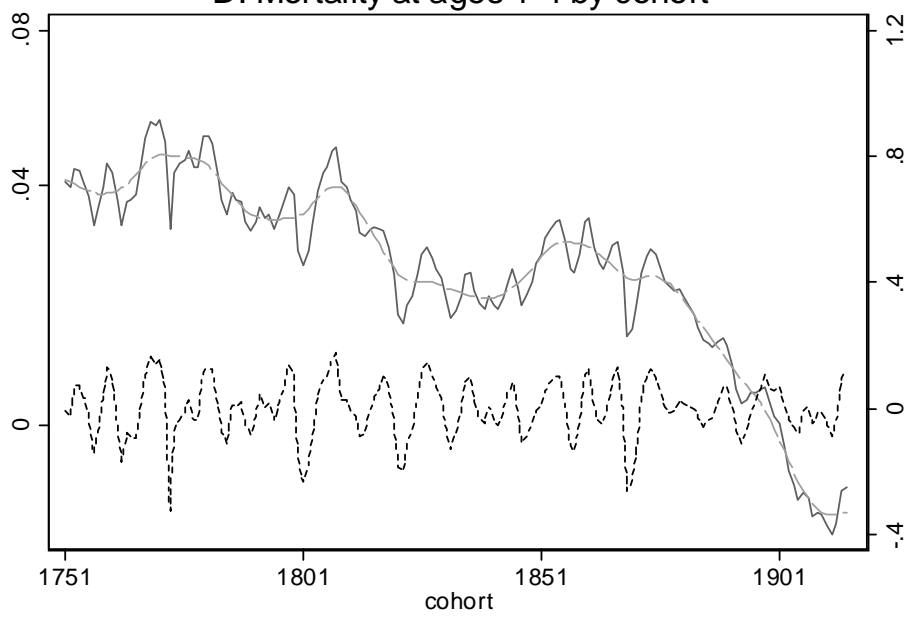


Figure 2. Illustration on how shocks in cohort's early life conditions and shocks in period conditions are matched with deviations from trend in age-specific mortality rates.

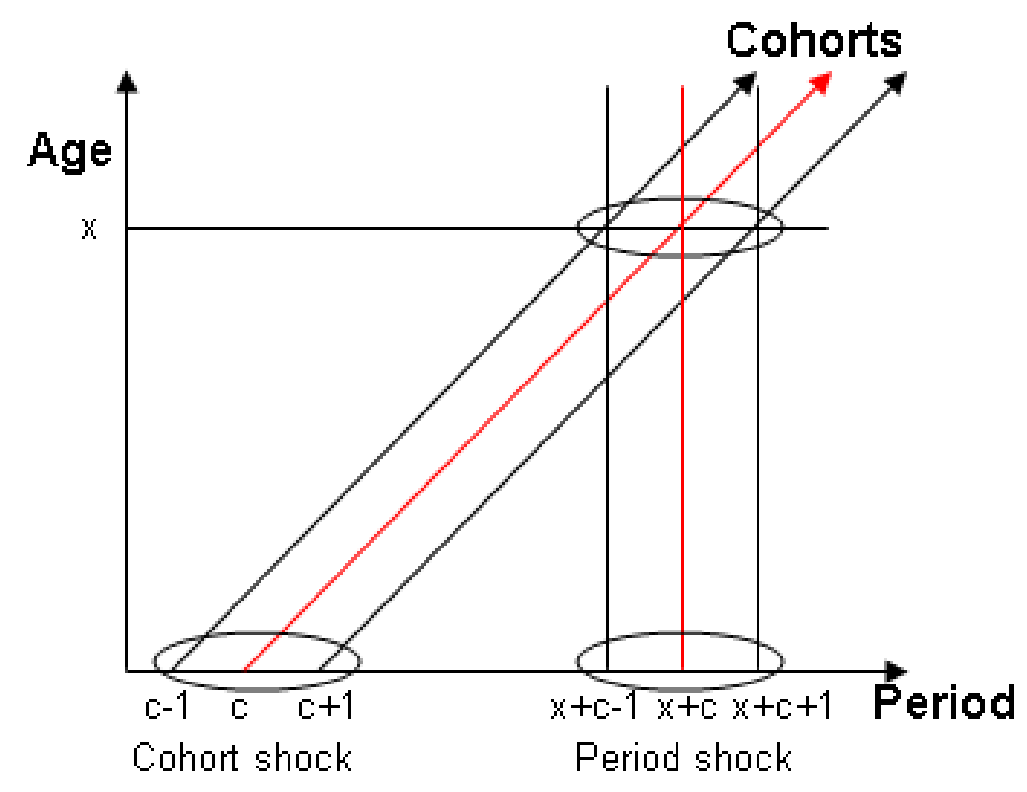


Figure 3. Illustration of the model that is used to simultaneously estimate the effects of cohort's early life conditions and period conditions on age-specific mortality.

Cohort shock 1:

Deviation from trend in cohort mortality at age 0 , cohort c

Cohort shock 2:

Deviation from trend in cohort mortality at ages 1-4, cohort c

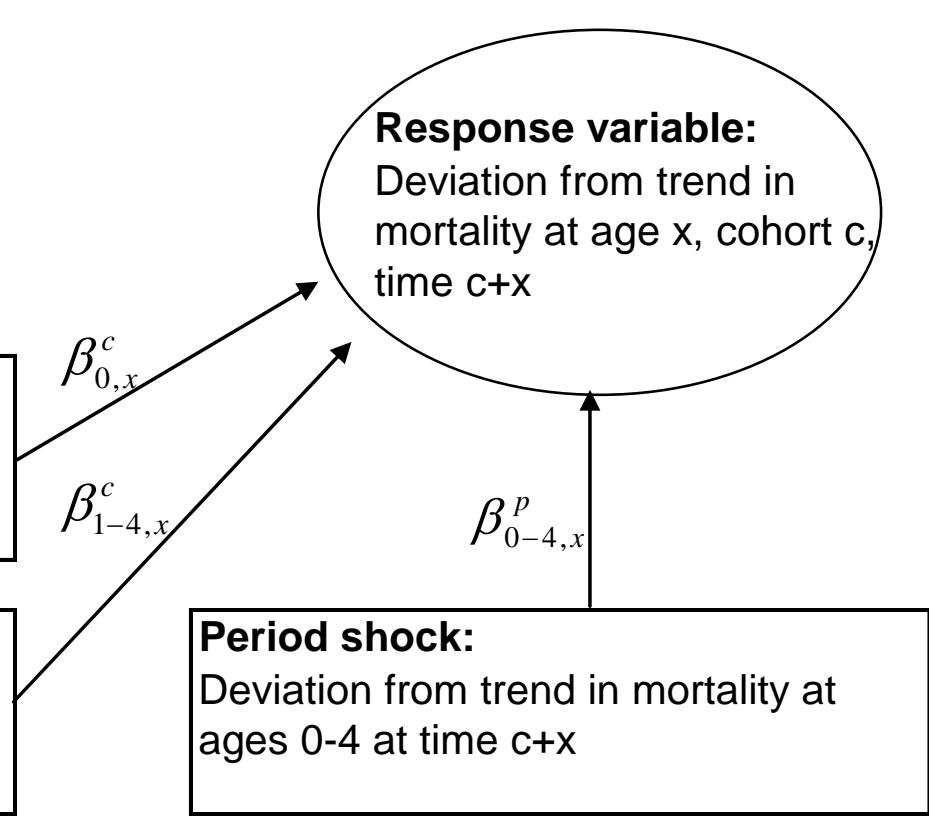


Figure 4. The effects on mortality by age of one standard deviation (S.D.) shocks in period and early life cohort mortality conditions measured from mortality between ages 0-4 in Sweden and England and Wales. Data: Human Mortality Database, cohorts 1751-1915 for Sweden and 1841-1915 for England and Wales.
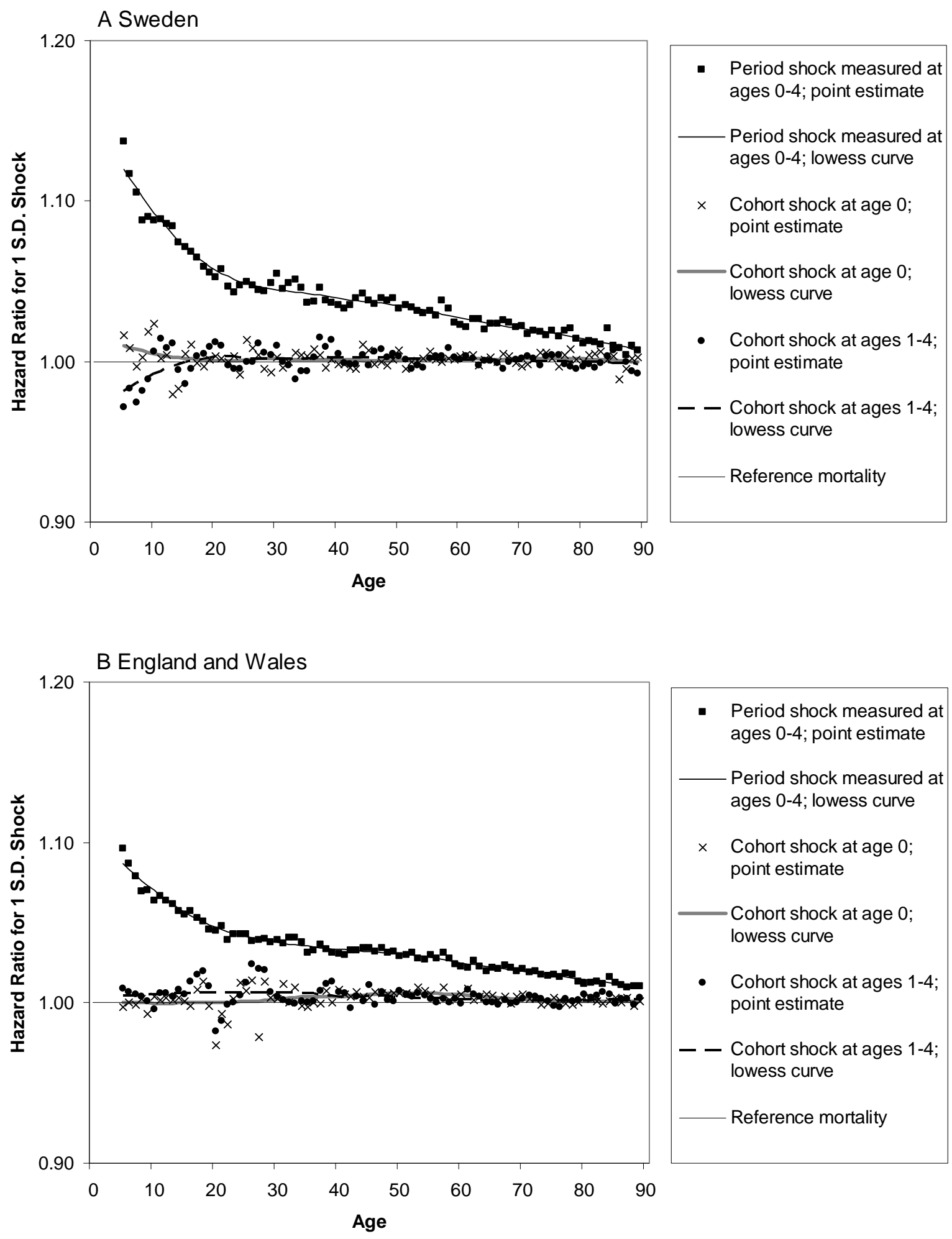

- Period shock measured at ages 0-4; point estimate

Period shock measured at ages 0-4; lowess curve

$\times \quad$ Cohort shock at age 0; point estimate

\section{Cohort shock at age 0;} lowess curve

- Cohort shock at ages 1-4; point estimate

- - Cohort shock at ages 1-4; lowess curve Reference mortality 
Figure 5. The effects of cohort and period shocks on mortality hazard ratio by age and country. Panel A: Effect of cohort mortality shock at age 0; Panel B: Effect of cohort mortality shock at ages 1-4; Panel C: Effect of period mortality shock at ages 0-4.

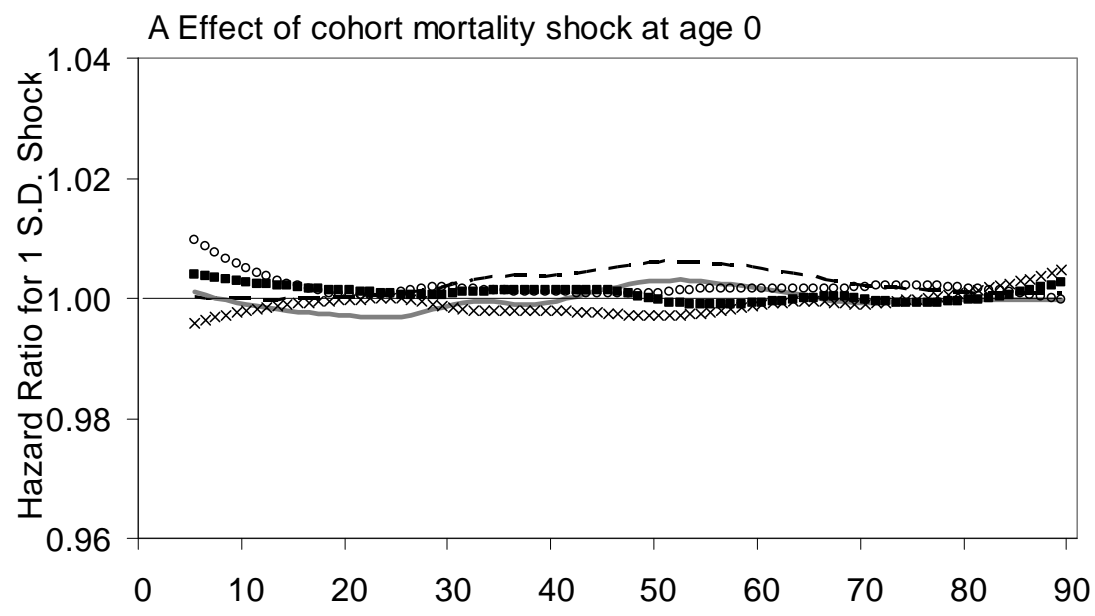

B Effect of cohort mortality shock at ages 1-4

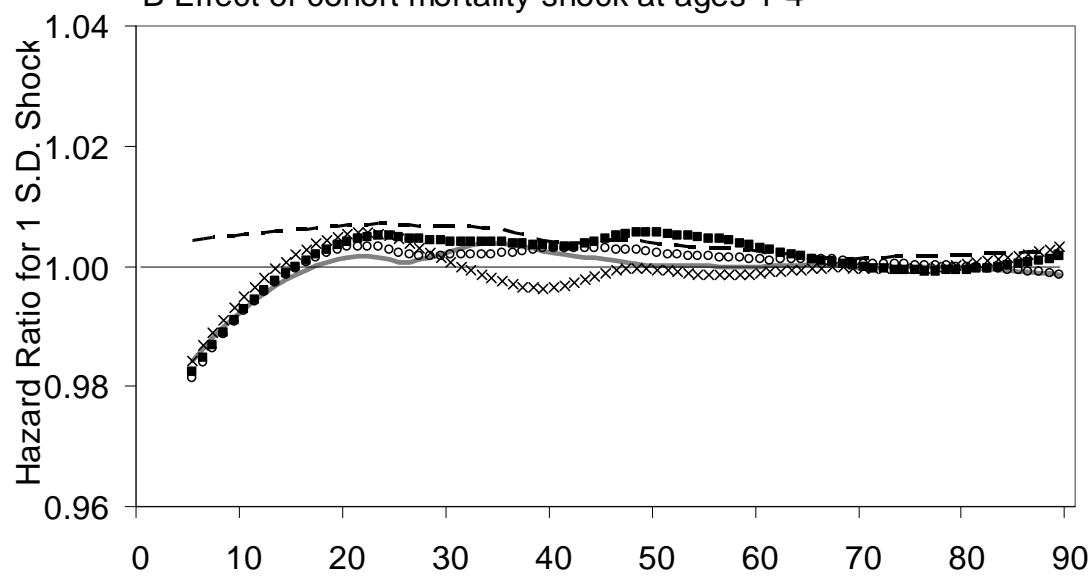

C Effect of period mortality shock measured at ages 0-4

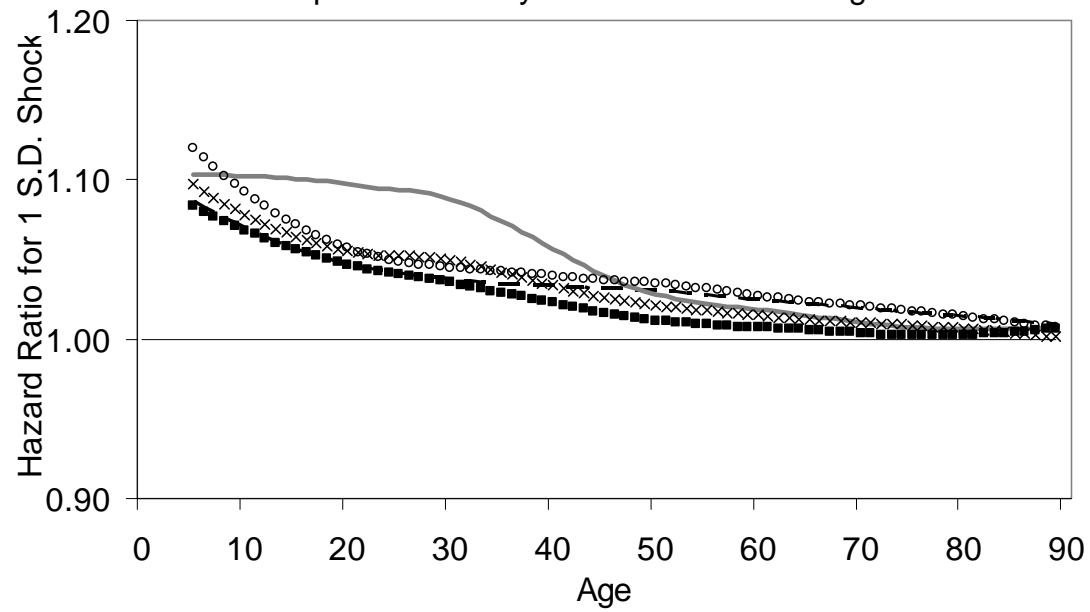


Figure 6. The effects of cohort and period shocks on conditional life expectancy. Cohort shocks are measured from cohort mortality at ages 0 and 1-4, and period shocks period mortality at ages $0-4$. The effects are calculated using the coefficients shown in Figure 5 and country specific year 1900 cohort life tables, and averaged over countries. The effects are scaled to represent the effect of three standard deviation shocks.

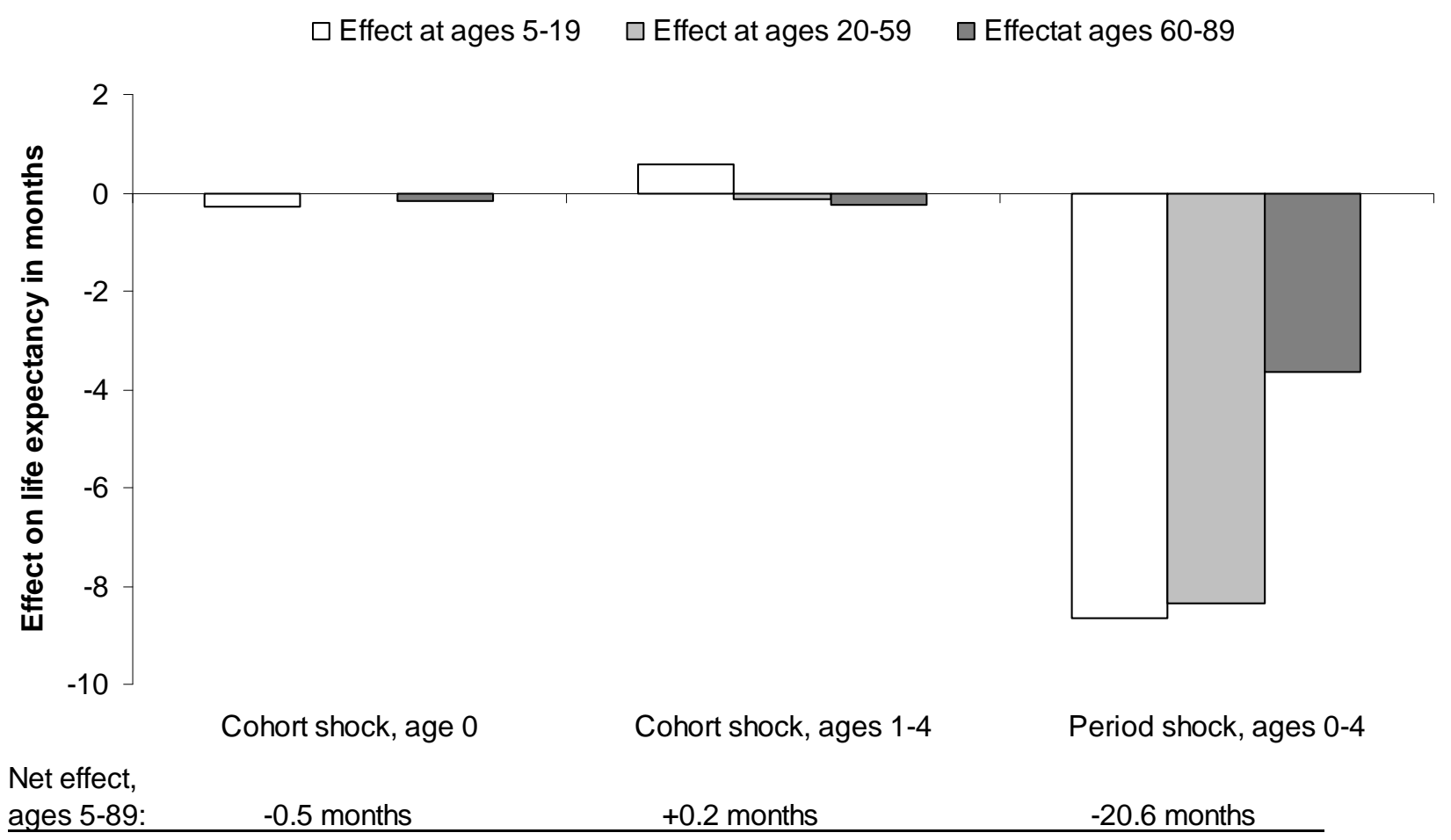




\section{NOTES}

${ }^{1}$ Research attempting to simultaneously estimate age, period and cohort effects can be seen as an exception. However I will not discuss the Age-Period-Cohort (APC) approach as the APC models are well suited for describing mortality over the three dimensions of age, period and cohort, but not well suited for analyzing the particular aspects of factors associated with period or cohort which produce the effects.

${ }^{2}$ The presented mechanisms are closely related to the typology presented by Preston, Hill and Drevenstedt (1998). Preston et al. identify four mechanisms that relate the risk of death in childhood and the risk of death in adulthood; these are (1) positive and direct, (2) positive and indirect, (3) negative and direct, and (4) negative and indirect. In the typology of this study, selection corresponds to (4), scarring to (1) and acquired immunity to (3). High risk of death early and late in life may be also indirectly related (2), through "correlated environments" so that better access to education and health care in childhood results in higher adult socioeconomic status and lower adult mortality. This study uses data aggregated at the national level, so such an effect is intractable.

${ }^{3}$ The magnitude of a one S.D. shock depends on whether one looks at relative or absolute deviations from trend. In absolute terms, one standard deviation increase in mortality would be largest for infant mortality. In relative terms, however, this is not the case as the changes are scaled to the mortality level.

${ }^{4}$ Here only the lowess curves are shown, not single-age coefficients. Including the coefficients for every single age would not change the results, but would make it very difficult to interpret the results.

${ }^{5}$ For Sweden, the effect on life expectancy at ages 5-89 for a 3 S.D. shock in infant mortality is -0.52 months, and for England and Wales, -0.78 months.

${ }^{6}$ The Human Mortality Database data shows that there was stalling or potentially even decrease in life expectancy for these cohorts. 